\title{
GÊNERO, CURRÍCULO E PEDAGOGIA DECOLONIAL: ANOTAÇÕES PARA PENSARMOS AS MULHERES NO ENSINO DE HISTÓRIA
}

\section{LARISSA COSTARD ${ }^{1}$}

\begin{abstract}
RESUMO: O trabalho proposto nesse artigo tem como objetivo central discutir apontamentos teóricos que nos permitam pensar gênero, currículo e ensino de História. Partindo de uma concepção de currículo de História na educação básica como um texto, ou narrativa que sinaliza determinadas concepções de história e dos atores sociais representados, e que por isso reflete relações historicamente situadas de poder na construção dos saberes que envolvem o processo de ensino e aprendizagem, é possível iniciar o debate com a noção de que as narrativas e perspectivas construídas nas salas de aula constituem matéria-prima fundamental para a formação das identidades sociais dos estudantes. Assim, entendendo os currículos como 'documentos de identidade', conforme sinaliza Tomaz Tadeu da Silva, a pesquisa gira em torno de questionar que histórias e que mulheres estão presentes na construção do saber histórico escolar, e especialmente que aportes podemos mobilizar para pensar currículos que rompam com uma história única das mulheres, ou seu apagamento nas narrativas da história escolar. O quadro teórico sugerido para debater a questão tem como base a ideia de problematizar a colonialidade do gênero, de acordo com as reflexões da filósofa argentina María Lugones, e a necessidade premente de pensar um currículo decolonial, à luz de Catherine Walsh, para uma interculturalidade crítica, amparando uma escrita escolar da história com enorme potência de diversidade, crítica e abertura para outras histórias.
\end{abstract}

Palavras-chave: história das mulheres, pedagogia decolonial, gênero e currículo, feminismo decolonial.

\section{Gender, curriculum and decolonial pedagogy: notes do think women in History teaching}

\begin{abstract}
This article has as primary goal debate theoretical approaches to discuss gender, curriculum and history teaching. Assuming that history's curriculum in basic education is a text, or a narrative, that shows certain conceptions of History and its agents and therefore reflects social relations historically built in terms of power and knowledge, it is possible to begin the debate with the notion that this History in school classes is something that founds the social identities of our students. So, the curricula are read as "identity documents" (as the author Tomaz Tadeu da Silva says), and because of that we have to question what kind of narratives of women are present in our History classes. This research wants to reflect on what theory we can use to design a curriculum that breaks the single history about women, or even the complete silence about their presence as history agent. Using the concept gender coloniality, from Maria Lugones, and the urgent need of a decolonial curriculum, as Catherine Walsh proposes, we can achieve a critical interculturality that alow us writing school history with enormous power of diversity, criticism and openness to other histories.
\end{abstract}

Keywords: women's history, decolonial pedagogy, gender and curriculum, decolonial feminism

\footnotetext{
${ }^{1}$ Doutora em História pela Universidade Federal Fluminense (UFF). Professora do Instituto de Aplicação
} da Universidade do Estado do Rio de Janeiro (UERJ). 
...Es en última instancia un sueño, pero uno que se sueña en el insomnio de la práxis. Esto se debe a que un individuo no puede decir que ha logrado la pedagogía crítica (o la pedagogía de-colonial) si deja de luchar por conseguirla. Peter McLaren

O artigo aqui exposto é um esforço surgido a partir de reflexões que a prática docente me colocou, especialmente nas atividades no Instituto de Aplicação Fernando Rodrigues da Silveira (CAP-UERJ) e nas orientações aos licenciandos em História no curso de graduação na Universidade do Estado do Rio de Janeiro (UERJ, campus Maracanã), e tem ocorrido em conjunto com os colegas do Laboratório de Ensino de História, na linha Espaços Educativos e Desigualdades, da qual faço parte. Contudo, gostaria de começar elucidando que o maior objetivo aqui não será de narrar ou relatar práticas específicas que venho desenvolvendo como professora de prática de ensino, mas sim um esforço de articular referenciais teóricos que têm nos informado quando pensamos na temática de gênero na escola. O estímulo a estas discussões vem da tentativa de elaborar uma visão e prática condizentes com uma inserção das mulheres como sujeitos históricos, rompendo com relações tradicionais de gênero. E, por que não dizer, colaborando assim para uma educação emancipadora, crítica e anti-machista.

Nesse sentido, proponho a divisão do artigo em três partes: uma primeira, reflexões no campo da teoria do currículo e o currículo de História na educação básica; na segunda, a noção de colonialidade e decolonialidade; e por fim, a articulação entre os dois campos na escrita curricular da História escolar.

\section{Para pensar os currículos de História na Educação Básica}

Pensar o currículo no ensino de História atualmente nos fomenta uma série de debates, cujo campo de reflexão se estende desde as reflexões teóricas até as experiências práticas que são realizadas, passando pelas políticas públicas, entre outras questões. Na impossibilidade de mapear com profundidade todos esses debates, especialmente considerando que não é o objetivo do presente artigo, proponho valorizarmos especialmente as questões apresentadas pelos autores que fizeram a crítica ao 
currículo como algo dado anteriormente à própria prática.

No bojo da crítica à lógica da racionalidade técnica na educação, que entende o professor como transmissor de um conhecimento produzido na academia (hierarquizando no processo o saber acadêmico de origem e os conhecimentos procedimentais), a crítica ao currículo tradicional e a valorização do saber docente ganham grande importância. Nessa lógica da racionalidade técnica, o currículo era compreendido dentro da dimensão organizativa: havia conhecimentos "universais" e "inquestionáveis", produzidos pela ciência, que já estavam dados e deveriam ser ensinados, e por isso, pensar o currículo representava administrar e distribuir os conteúdos pelas séries, de acordo com seu grau de abstração (Monteiro, 2007). Entre as muitas críticas que Ana Maria Monteiro faz a essa lógica da racionalidade técnica, destaco aqui a que se refere ao saber escolar como algo não questionado, uma reprodução de saber externo à escola, e a noção de seleção cultural quando se trata do currículo. Da primeira, deriva a discussão de Monteiro, amparada na Nova Sociologia da Educação ${ }^{2}$, sobre os saberes escolares:

conhecimento com configuração cognitiva própria, relacionado mas diferente do saber científico de referência, e que é criado a partir das necessidades e injunções do processo educativo, envolvendo questões relativas à transposição didática e às mediações entre conhecimento científico e conhecimento cotidiano, bem como às dimensões histórica e sociocultural numa perspectiva pluralista (Monteiro, 2007, p14).

Como se percebe pelo trecho destacado da autora, sua análise de uma pedagogia crítica vincula a essa discussão sobre o saber escolar a ideia de um professor-autor, dotado de um saber específico - o saber docente - que se constitui não apenas pelo conhecimento teórico da ciência de origem e da pedagogia, mas também no (e para) o exercício da profissão docente, produzidos e mobilizados na ação. Um possível exercício que Monteiro nos estimula a fazer é pensar na ideia de professor-pesquisador, tanto do ponto de vista de que este não produz apenas saber docente, mas também em sua matriz disciplinar de referência. O professor que domina o processo de produção

\footnotetext{
2 Entre os autores que Ana Maria Monteiro discute em Professores de História: entre saberes e práticas, destaco L. Shulman, M. Tardif, C. Lessard, L. Lahaye e M. Develay, A. Chervel, Y. Chevallard, J. C. Fourquin, I. Goodson.
} 
de pesquisa histórica e sua metodologia é capaz de manipular o saber de referência com mais eficácia no processo de mediação didática, além do fato de que é também epistemólogo, escrevendo a História escolar - e não apenas reproduzindo conhecimento produzido por outros. Como afirma Selva Guimarães, "lecionar é inventar saberes próprios à situação de trabalho" (Fonseca, 1997, p. 10).

Parte do saber docente, retomando o trecho citado de Monteiro, passa pela articulação dos saberes disciplinares, curriculares, pedagógicos e práticos no processo de didatização do conhecimento, entendida a criação do saber (a ser) ensinado. Com isso, entra em cena a segunda questão que é apresentada por Monteiro e amplamente discutida por outros autores, como Alice Lopes e Miguel Arroyo: a transposição didática (ou mediação didática) e a seleção cultural no currículo.

De acordo com essa pedagogia crítica, é preciso levar em consideração que as relações na escola, e entre escola-sociedade-cultura, determinam distintas leituras dos textos curriculares oficiais, originando um "currículo na ação", ou seja, que se forja na prática, com distintas formas de mediação ${ }^{3}$ didática e com seleção dos temas e conteúdos que serão efetivamente ensinados e aprendidos, de acordo com as injunções e demandas de cada realidade escolar. Ou seja, há currículos reais que são executados e que se relacionam mais ou menos com os currículos prescritos de acordo com a seleção cultural feita pelos professores.

Levando em consideração esses temas, especialmente a ideia de que o currículo é seleção, um grande salto qualitativo na nossa análise nesse momento é a apreensão de Tomaz Tadeu da Silva de que os currículos são documentos de identidade.

O autor compartilha a noção semelhante à de seleção cultural no currículo real, e podemos compreender que seu ponto de partida se dá na pergunta: há um currículo preparado, pronto, a ser descoberto? A partir da negativa de resposta a essa pergunta, evidentemente, Silva propõe que discutamos as teorias do currículo sob o lema: menos ontologia do currículo e mais história dele. Ou seja, é preciso pensar menos no suposto "ser" do currículo (o que ele é e que a teoria descobrirá, teorizar sobre algo

\footnotetext{
${ }^{3}$ Opto pela utilização do termo mediação, em lugar de transposição, de acordo com a discussão apresentada por Alice Lopes: o termo transposição pode remeter a ideia de um saber que é transposto de fora da escola para dentro dela, e como aqui considero que o processo de transformação do saber a ensinar em saber ensinado é parte da escrita da História escolar, é (re)construção de conhecimento, entendo que o termo mediação evita a sensação de que o conhecimento é produzido fora da escola (Lopes, 1997).
} 
que é, que existe a priori) e mais em como ele vem sendo definido historicamente, o que se espera que ele seja em distintos contextos socioculturais e escolares (Silva, 2016).

Desta maneira, o elemento definidor de nossa reflexão sobre os currículos de História na educação básica passa pela pergunta: o que deve ser ensinado? A resposta deve levar em consideração o que esperamos que nossos alunos se tornem, o fato de que o conhecimento está vitalmente relacionado com o que nos tornamos. Quem ensina também afeta quem aprende (Candau, 2013).

Aqui me permito fazer uma pequena digressão, e invocar temas fundamentais para o ensino de História, como consciência histórica, cultura histórica e memória, e autores como Jörn Rüsen e Jacques Le Goff, por exemplo. Por cultura histórica, em linhas muito gerais, pode-se entender um conjunto de bens culturais que discutem o passado ou que o utilizam como fonte, não sendo apenas o conhecimento histórico formalmente produzido de acordo com métodos e regras epistêmicas específicas (Rocha, 2014). De acordo com Jörn Rüsen, a cultura histórica tem dimensões cognitivas o conhecimento histórico científico -, mas também estéticas e políticas - arte que utiliza o passado como matéria prima ou o representa, e identidades coletivas e políticas, respectivamente. Todos esses campos se relacionam entre si, e são matéria-prima de formação da consciência histórica. Entendendo consciência histórica de acordo com Jörn Rüsen, como a capacidade de atribuição de significado ao fluxo da experiência humana no tempo, uma constante interpretação e reinterpretação de si e do mundo que orienta a ação (de acordo com intenções) desse mesmo sujeito no mundo (Rüsen, 2011), e que a memória e os bens culturais da cultura histórica não aparecem por acaso, espontaneamente, pensar o que se ensina nas aulas de História tem dimensão muito relevante. Tomando de empréstimo a discussão de Jacques Le Goff de que a memória social está eivada de tensões sociais, entre aquilo que se escolhe lembrar e o que se escolhe esquecer, ou seja, toda memória tem sua parte de amnésia social (Le Goff, 1990), ou a de Douglas Kellner, de que os padrões culturais que conformam nossas identidades e visão de mundo estão em constante disputa (Kellner, 2004), se constroem socialmente, não estão dados como algo natural.

A História escolar, como um dos elementos da cultura histórica, tem relevante papel na formação do sentido que damos à experiência do homem no tempo, na for- 
mação da consciência histórica. Da mesma maneira, o conhecimento histórico dialoga em todo tempo com a memória social, o que desejamos lembrar e o que não podemos permitir que se esqueça. Se cabe ao historiador tocar constantemente na amnésia social, como provoca Le Goff, é preciso que encaremos de frente a tarefa que nos é colocada por oficio: a História que contamos é um dos elementos a fornecer matéria-prima para a forja das identidades sociais. E voltando a Tomaz Tadeu Silva: que matériasprimas temos fornecido aos nossos estudantes no processo escolar - que tem como função, além da qualificação e socialização, a subjetivação (Biesta, 2012)? Os currículos são também, portanto, questões de identidade. E por isso, selecionar o que aparece nos currículos é também questão de disputa, questão de poder: quais são as identidades sociais e agentes que aparecem nos meus currículos? Em que medida corroboram ou questionam o consenso, a hegemonia?

Vejam bem que aqui não se trata de uma falsificação da História para proselitismo político, mas o constante questionamento de que, se todo currículo na prática é seleção, quais histórias tenho selecionado para contar? E deste modo, o "o que contar" está submetido a constante escrutínio do "por que / para que contar" (Silva, 2016). Assim, Tomaz Tadeu da Silva chama atenção para dois níveis de relações de poder que tocam o processo de seleção cultural no currículo. O primeiro é o fato de que selecionar é um ato de poder, e o segundo é que os conhecimentos que nos informam e que ensinamos também são frutos de relações de poder em epistemologias específicas. Os currículos que construímos produzem narrativas sobre a História. A partir disto, é interessante observar o aparato conceitual que Tomaz Tadeu Silva mobiliza para pensar uma teoria crítica do currículo: o vínculo é o saber-poder-identidade. Interrogar cotidianamente os conhecimentos que mobilizamos no sentido de perceber quais foram as relações de poder - que incluem aí inclusive o poder de determinar epistemologia - que estão em sua base.

Nesse momento acredito que já seja interessante entrarmos na seara da colonialidade, nossa segunda esfera, e depois retornamos aos documentos de identidade.

\section{Colonialidade, decolonialidade e pedagogia}

Em meados dos anos 1990, no bojo da crítica às teorias pós-coloniais, formou- 
se nos EUA um grupo de intelectuais latino-americanos cujo objetivo foi pensar histórica-filosófica-sociologicamente a experiência de incorporação forçada da América latina (inicialmente) no sistema mundo capitalista a partir de um projeto de poder que chamaram de colonialidade/modernidade. Pensaram assim, de maneira complexa, o que analiso que seja a concepção do modo-de-produção capitalista não exclusivamente do ponto de vista econômico, mas como um modo-de-produção de vida - que inclui também a dimensão econômica - e que se consolida como um projeto de dominação total: poder, epistemologia, ontologia, produção, e que não apenas se entrecruza, mas se funda numa imbricação inseparável entre a dominação de classe, a racialização e a generização ${ }^{4}$. Esse grupo, chamado Proyecto Modernidad/Colonialidad/ Decolonialidad, tem como principais nomes autores latino-americanos. Para discussão aqui apresentada, me concentrarei especificamente na definição de colonialidade do poder, do peruano Anibal Quijano, na noção de colonialidade do gênero, de María Lugones, e na proposta de uma pedagogia decolonial, de Catherine Walsh.

De acordo com Aníbal Quijano, o padrão de poder capitalista eurocentrado e global está estruturado em relações de dominação, exploração e conflito na disputa pelo controle de quatro âmbitos da existência humana: trabalho, autoridade coletiva, subjetividade e intersubjetividade, sexo, seus recursos e produtos. O poder capitalista global se organizou - e se organiza - em torno dos eixos da colonialidade e modernidade. A partir da leitura dos autores, podemos considerar que a colonialidade se apresenta em cinco esferas: poder, ser, saber, cosmogonia e gênero.

A colonialidade do poder se inscreve na esfera já citada do controle de todos os âmbitos da existência humana. Ela inventa e introduz a classificação da população do planeta em termos de raça (uma ficção), reposicionando relações de superioridade e inferioridade estabelecidas através da dominação: redimensiona o que é a humanidade em termos raciais, desumanizando parte dela (das identidades geoculturais e soci-

\footnotetext{
4 Utilizo aqui o termo "generização", como tradução livre de "engenerizar", em espanhol, de Maria Lugones, que por sua vez cria o neologismo como tradução para o termo "gendered". Segundo Lugones, gendered faz referência a negociação subjetiva dos arranjos de masculinidade e feminilidade, à designação de gênero e ao fato de que percepção própria sobres categorias e identidades de gênero fazem parte dessa negociação. De acordo com a autora, o uso do termo engenerar, em espanhol, apesar de não existir na Real Academia Espanhola, é freqüente desde os anos 1990 para dar conta dos processos subjetivos e intersubjetivos do gênero. Em português, noto que os trabalhos acadêmicos que discutem gênero têm utilizado o neologismo generização como tradução para gendered e genderization. $\mathrm{O}$ sentido é o da atribuição de gênero [ou características de] a algo/alguém.
} 
ais inventadas e periféricas), o que o grupo entende como colonialidade do ser (ontológica). Essa produção não é apenas uma classificação racial, mas um fenômeno abarcador de toda experiência social no sistema de poder da colonialidade capitalista, uma vez que contribui, inclusive, para que as populações inferiormente racializadas sejam distintamente inseridas e exploradas no sistema mundial (por exemplo, o trabalho assalariado capitalista é resguardado ao branco europeu, enquanto aos africanos e indígenas, "menos humanos", a exploração servil ou escravista é padrão recorrente). A racialização no projeto colonialidade implica em um processo de representação de si e do outro, ou seja, na produção de conhecimentos, e produz, como irmã gêmea da colonialidade ontológica, a colonialidade do saber, a epistemológica. A perspectiva cognitiva eurocentrada (de todos aqueles que são educados sob a hegemonia do capitalismo mundial) tende a naturalização das perspectivas de poder instituídas, a partir de noções como eficiência, competição e evolução. Assim, como parte do projeto de colonialidade/modernidade capitalista, a hegemonia de uma epistemologia eurocentrada, que culmina na colonialidade da cosmogonia: a relação homem-natureza, filosofias e religião também tomam as relações de poder econômico e político eurocentrada da colonialidade global. Por fim, ponto de grande debate entre os próprios autores do grupo, a colonialidade do gênero, que em Quijano passa por um processo de dominação do sexo, seus produtos e recursos (Castro-Gómez e Grosfoguel, 2007).

María Lugones, filósofa argentina também pertencente ao Modernidad/Colonialidad, critica essa interpretação, especialmente pelo fato de ser essencialmente biológica, binária e heterossexual: o que define os papéis de gênero é a possibilidade de se apropriar dos recursos e produtos do sexo. Além disso, a autora afirma que Quijano já partiria de uma essencializada superioridade entre homens e mulheres, que permitiria que os primeiros se apropriassem dos produtos sexuais das segundas, pressupondo uma distribuição patriarcal do poder. Gênero derivaria da sexualidade quase exclusivamente, restando pouco espaço para a ideia de uma construção social dos papéis que permitem as referidas apropriações (Lugones, 2008). Perigosamente dá por fato que a disputa pelo controle do sexo é uma disputa entre homens, que as muIheres não participam como agentes da disputa (e se não há agência, há resistência?). O que autora pretende aprofundar é que tanto raça quanto gênero (apreendido no âmbito do dimorfismo sexual, binarismo e hierarquia), apesar de narrados como ante- 
riores ao capitalismo, são produções míticas dele. Isso dá, inclusive, no espectro do grupo modernidade e colonialidade, outro grau à noção, cara a um feminismo, de interseccionalidade, a partir da noção de que não só raça, classe e gênero se atravessam em um mesmo indivíduo, mas como categorizações sociais, foram inventados juntos, no âmbito da consolidação do capitalismo global eurocentrado.

Lugones resgata dois elementos para elaborar a ideia de que a construção da categoria mulher, com papel de gênero definido - a partir de ideias como passionalidade, fragilidade, vida privada - não estão inscritos em qualquer natureza individual e subjetiva. Sua argumentação de que gênero é uma invenção moderna gira em torno de dois exemplos: a existência pessoas intersexuais e as experiências de organização social anteriores à colonização.

No que diz respeito aos indivíduos intersexuais, baseada em Julie Greenberg, Lugones se refere àqueles que apresentam, no espectro de tudo que define a categoria sexual (cromossomos, gônadas, morfologia externa, morfologia interna, padrões hormonais, fenótipo, sexo atribuído e auto-atribuído), ambigüidades que não se enquadram em um ou outro sexo definido - masculino ou feminino. Greenberg afirma que (em 2002) eram identificados como intersexuais entre 1 e $4 \%$ da população dos EUA. Assim, Lugones conclui que o dimorfismo e o binarismo de gênero são uma das características do lado visível do sistema moderno/colonial de gênero. Em sociedades tribais anteriores à colonização, os indivíduos intersexuais eram reconhecidos e não assimilados na classificação binária, ou seja, em outras tradições culturais as pessoas intersexuais não são "corrigidas" ou "normalizadas/normatizadas" (Lugones, 2008). O binarismo e a heterossexualidade compulsória estão, nessa ótica, historicamente relacionados à sociedade moderna eurocentrada e capitalista, com a necessidade de eficiência na produção dos produtos sexuais. A divisão sexual binária não está exclusivamente baseada na biologia, e o sistema eurocentrado global inverte os vetores ao afirmar que a identidade (gênero) é construída em cima da biologia (sexo), e o gênero antecederia à definição dimórfica pelos recursos biológicos, segundo Lugones.

Segundo elemento apresentado pela filósofa argentina, e que pode ser particularmente interessante para as aulas de História, diz respeito ao conhecimento de sociedades cuja lógica de organização não se assentava num sistema opressivo de gênero: as experiências de igualitarismo ginecrático ou igualitarismo não-generizado. Com base 
nas pesquisas de Oyeronké Oyewùmi (A Invenção das Mulheres, 1997), Lugones usa o exemplo da sociedade ioruba, antes da colonização, na qual gênero não era um princípio organização social. Oyewùmi afirma inclusive que gênero só começou a aparecer como categoria na sociedade ioruba quando os estudos foram traduzidos para o inglês, caracterizando um processo de dominação ocidental sobre a documentação e interpretação do mundo. No glossário ioruba, a tradução de obinrin para fêmea/mulher e okunrin para macho/homem seria um equívoco, porque originalmente os vocábulos não têm o mesmo significado que a apreensão de gênero dicotômica e hierárquica da epistemologia eurocentrada. Os iorubas não entendiam essas categorias como binariamente opostas. A introdução da categoria mulher, no sentido biologizante do gênero, teria sido - junto com a máquina burocrática - o elemento de associação dos homens colonizados com os colonizadores na disputa pelo poder na esfera pública, recémcriada pela própria colonização, que excluiu as (também recém-criadas) mulheres dos papéis de liderança, do acesso à propriedade e outros espaços econômicos, largamente exercidos anteriormente. A imposição do Estado colonial é a imposição também da estrutura patriarcal de relações sociais (a autora chama de Estado colonial patriarcal). A colonização foi o processo de subordinação racial e também de gênero. ${ }^{5}$

Além desse exemplo do igualitarismo não-generizado dos iorubas, Lugones resgata as experiências dos povos originários da América (baseada nos trabalhos de Paula Gunn Allen, The Sacred Hoop. Recovering the feminine in american indian traditions, 1992) para caracterizar as experiências de igualitarismo ginecrático. Retomando a importância da espiritualidade na visão de mundo indígena, é interessante observar como as forças que moviam o universo eram femininas, e todo o sagrado derivava da mulher. O comando das sociedades indígenas era exercido por uma mulher, na chefia interna, e por um homem, na chefia externa. A primeira comandava a tribo, garantindo seu funcionamento e harmonia, administrando os assuntos internos, e o segundo cuidava dos assuntos entre a tribo e os que não pertenciam a ela. Os gêneros não eram atribuídos em termos biológicos, mas sim pelos papéis que desenvolviam com base na propensão, inclinação e temperamento. Da mesma forma, utilizando dados

\footnotetext{
${ }^{5}$ A autora faz ainda aqui um debate muito relevante para as temáticas de violência e objetificação das mulheres de cor, que envolve a desumanização e sexualização da colonizada, considerando que para o colonizador, mulher é a branca européia e burguesa. As colonizadas estariam, por isso, mais submetidas a toda sorte de violência.
} 
fornecidos por Allen, Lugones afirma que oitenta e oito tribos reconheciam a homossexualidade. $^{6}$

Segundo Lugones, substituir a "pluralidade espiritual ginecrática" por um ser supremo masculino teria sido fundamental para sua submissão no processo de colonização, e por isso, a lógica hierárquica de gênero que inferioriza a mulher indígena esteve intimamente ligada à dominação e à transformação da vida tribal. Citando Allen, Lugones resume o processo em quatro fases:

1. La primacía de lo femenino como creador es desplazada y reemplazada por creadores masculinos. (1986/1992: 41).

2. Se destruyen las instituciones de gobierno tribal y las filosofías en las que están fundadas, como sucedió entre los Iroquois y los Cherokee (41).

3. La gente "es expulsada de sus tierras, privada de su sustento económico, y forzada a disminuir o abandonar todo emprendimiento del que dependen su subsistencia, filosofía y sistema ritual. Ya transformados en dependientes de las instituciones blancas para su supervivencia, los sistemas tribales no pueden mantener la ginocracia cuando el patriarcado - en realidad su supervivencia - requiere la dominación masculina (42).

4. La estructura del clan debe ser reemplazada de hecho, sino en teoría, por la familia nuclear. Con este truco, las mujeres líderes de los clanes son reemplazadas por oficiales machos elegidos y la red psíquica creada y mantenida por la ginecentricidad no-autoritaria basada en el respeto a la diversidad de dioses y gente es destruida. (42) (Lugones, 2008. p.89-90).

Assim, em um só processo histórico, a dominação econômica é amparada pela racialização dos indígenas e o igualitarismo ginecrático é substituído por uma estrutura de dominação e cosmologia que tem como hierarquia de gênero a superioridade do homem sobre a mulher. Ao mesmo tempo em que reorganiza politicamente os clãs e se apropria de seus recursos, impede o recurso a uma vida e visão de mundo originais como forma de organização para a resistência. Os homens generizados no processo de colonização, tornados patriarcais, se tornariam o braço interno do colonizador branco no seio das sociedades colonizadas.

Esses exemplos mencionados por Lugones são interessantes para aprofundar o debate acerca dos papéis de gênero tradicionalmente designados às mulheres: a inabi-

\footnotetext{
${ }^{6}$ María Lugones faz a ressalva no uso do termo para o fato de que homossexualidade e lesbianismo pressupõe a compreensão dimórfica e dicotômica de gênero, não existente nas cosmologias indígenas.
} 
lidade para a esfera pública, que demanda racionalidade escassa no gênero feminino, a aptidão para o afeto e a família, a honra feminina a partir do cuidado com o espaço doméstico, a fragilidade, a submissão e a necessidade de cuidado e tutela. Todas essas dimensões atribuídas à mulher em associação com a biologia, como se fossem parte da natureza feminina, foram construídas historicamente: um lugar específico, a Europa; um sistema específico, o capitalismo colonial global. Os papéis de gênero, e o próprio conceito de gênero, não são natureza, não são essência: são relações de poder.

\section{Pedagogia decolonial e a questão de gênero}

Agora, já colocadas algumas questões relevantes para pensar currículo e a colonialidade de gênero, proponho retomar as duas dimensões em diálogo, um exercício de pensar o currículo e gênero à luz de uma pedagogia decolonial, conceito da pedagoga equatoriana Catherine Walsh.

O conceito, baseado na noção de interculturalidade crítica, é proposto por Walsh na crítica à perspectiva do multiculturalismo neoliberal na América Latina nos anos 1990, contexto das políticas do Banco Mundial para a educação e diversidade latinoamericana. Esse multiculturalismo da razão neoliberal é apreendido pela autora como uma lógica da (re)colonialidade. Sua base é o conceito de cultura antropológico, que numa universalização humanista "iguala" todas as culturas em termos de valor, criticando a hierarquia do progresso tão comum na explicação das diferenças sociais no século XIX. No entanto, por mais que essa crítica ao progresso precise ser feita, o multiculturalismo da razão neoliberal acaba por jogar a diferença cultural para um plano de essência humana, mitigando que, ainda que a cultura seja típica da humanidade, a construção da diferença é social e historicamente dada. Ao essencializar a diferença cultural, o multiculturalismo da razão neoliberal neutraliza e esvazia o significado das relações de poder que constroem essas diferenças, e tem como principal efeito social o integracionismo: abraça as diferenças sociais, celebrando-as, promovendo o controle dos conflitos étnicos sem questioná-los, sem interrogar os imperativos econômicos e sociais que estabilizaram o status quo. Além disso, no bojo da crise da tradição do Estado-nação, incluiu os grupos de diversidade historicamente excluídos na lógica de mercado (Walsh, 2008). 
Para uma pedagogia efetivamente crítica, Walsh, assim como Tomaz Tadeu Silva, parte do seguinte pressuposto: não basta celebrar as diferenças (ainda que tolerância e respeito sejam efeitos mais que desejáveis), mas é preciso questioná-las. Somente a compreensão da construção social das diferenças possibilita o potencial crítico para efetivamente transformar a realidade que produz as desigualdades. Pensar a construção dessas diferenças e seus efeitos sociais historicamente, desnaturalizandoas, num movimento de compreensão de que a identidade se constrói relacionalmente. Assim, a palavra de ordem não é o multiculturalismo neoliberal, mas sim a interculturalidade crítica, cuja origem está nos movimentos sociais étnico-raciais, e que tem como objetivo central denunciar a assimetria social de poder na construção social das diferenças. Segundo a autora, a interculturalidade crítica busca suprimir essa assimetria social e a discriminação cultural que inviabilizam uma autêntica diversidade cultural, um autêntico diálogo intercultural.

... buscan alternativas a la globalización neoliberal y a la racionalidad occidental, y que luchan tanto para la transformación social como para la creación de condiciones de poder, saber y ser muy distintas. Pensada de esta manera, la interculturalidad crítica no es un proceso o proyecto étnico, ni tampoco un proyecto de la diferencia en sí. Más bien y como argumental Adolfo Albán, es un proyecto que apunta a la re-existencia y a la vida misma, hacia un imaginario "otro" y una agencia "otra" de con-vivencia - de vivir con - y de sociedad (Walsh, 2008, p.10).

O resultado dessa preocupação, que é política e social, passa também pelas esferas do saber e se preocupa com a exclusão, negação e subalternização epistemológica-cognitiva de determinados sujeitos sociais. É, portanto, um processo também de "desaprender o aprendido para tornar a aprender" (Walsh, 2008, p.12), andando de mãos dadas com o projeto de de-colonialidade.

La interculturalidad crítica y la de-colonialidad, en este sentido, son proyectos, procesos y luchas que se entretejen conceptualmente y pedagógicamente, alentando unas fuerza, iniciativa y agencia éticamoral que hacen cuestionar, trastornar, sacudir, rearmar y construir. Esta fuerza, iniciativa, agencia y sus prácticas dan base para lo que nombro a continuación de pedagogía de-colonial. (Walsh, 2008, p. 13). 
Uma pedagogia decolonial teria como objetivo, portanto, visibilizar os dispositivos de poder e questionar as ausências de grupos sociais em nossas narrativas sobre a História da humanidade. Não basta apenas "adicionar" essas culturas, como adornos de homenagem à diferença, mas colocá-las em relação umas com as outras. Urge, inclusive, não apenas incluir os grupos subalternos em uma epistemologia que não foi projetada para que eles tenham dignidade como agentes históricos, mas questionar, inclusive, as raízes dessa epistemologia. Como consequência, é urgente pensar a subalternização dos grupos dominados nas aulas de História como produtos de disputas de poder historicamente dadas.

Apoiada em Paulo Freire e Frantz Fanon, a pedagogia decolonial de Catherine Walsh se afirma na dimensão de que educar é um ato político, com potência emancipadora e transformadora, e a ideia de que a humanização (que em Freire está relacionada com a ação consciente) pressupõe a de(s)colonização (questão central em Fanon). Citando Fanon, em Os Condenados da Terra, a autora destaca:

La descolonización no pasa jamás inadvertida puesto que afecta el ser, modifica fundamentalmente al ser, transforma a los espectadores aplastados por la falta de esencia en actores privilegiados, recogidos de manera casi grandiosa por la hoz de la historia. Introduce en el ser in ritmos propio, aportado por los nuevos hombres, un nuevo lenguaje, una nueva humanidad. La descolonización realmente es creación de hombres nuevos. Pero esta creación no recibe la legitimidad de ninguna potencia sobrenatural: la 'cosa' colonizada se convierte en hombre en el proceso por el cual se libera (Fanon, p.31 / Walsh, 2008, p.22).

Os professores podem ter nesse processo o papel (e responsabilidade) de ajudar nesse despertar. Como professores de História, repensar a ótica e as escolhas que temos feito em termos de currículo é questionar como temos contribuído para esse processo. Ainda que a temática central de Walsh em seus artigos seja a dimensão étnico-racial, sua noção de pedagogia decolonial é interessantíssima para pensarmos também a dimensão da colonialidade do gênero, e as possibilidades de questionarmos a construção histórica desses gêneros. Se, a partir de Walsh e Silva, é possível afirmar que temos um currículo racialmente enviesado, no qual a identidade branca é a referência invisível de toda a dimensão étnico-racial, arrisco-me a dizer que temos também, atravessando essa dimensão colonial, um currículo enviesado em termos de gê- 
nero. O texto curricular é colonizado também no sentido da colonialidade do gênero. $E$ a partir disso retomo a pergunta: quais mulheres-históricas temos fornecido como matéria-prima para a construção da identidade social de nossos estudantes? De que maneira nossa prática se insere na disputa pela formação da consciência histórica, dialoga com as tensões sociais dos produtos da cultura histórica? Qual lugar temos reservado para as mulheres na História em nossos textos curriculares? Repensar as histórias de mulheres que temos contado à luz de uma pedagogia decolonial na prática representa fortalecer

la creación de estructuras socio-educativas que equipan los 'oprimidos' con las herramientas necesarias para desvelar las raíces de su opresión y deshumanización, identificar sus estructuras, y actuar sobre ellas, también son componentes céntricos (Walsh, 2008, p.19).

Pedagogia decolonial, como um exercício, como uma nova forma de olhar a História, como parte da práxis. No quadro da proposta de uma pedagogia decolonial, encerro com duas possibilidades práticas, sugestões que apresento como colaboração e não prescrição, na expectativa de que sejam o início de uma longa lista de esforços, construída coletivamente.

1á: uma pedagogia decolonial deve fazer o eterno movimento de historicizar as diferenças e as relações sociais, apresentadas também como relações de poder. Assim, pensar a crítica ao papel esperado para as mulheres na História é retirá-las do gineceu de Atenas: apresentá-las como seres políticos, do espaço público, intelectuais, agentes da História, das revoluções e das reformas, não apenas pela silenciosa resistência cotidiana e doméstica (que também é importante), mas multiplicando as visões e os lugares sociais que as mulheres ocupam e ocuparam na História, e que não podem e não devem ser alvo da amnésia social. Deste modo, a visão tradicional da mulher frágil, passional e doméstica fica também compreendida em seu tempo e lugar histórico, e não como natureza;

2a: decolonizar as epistemologias e processos de trabalho pedagógico: incluir, revitalizar e revalorizar os saberes ligados aos grupos subalternizados. Abraçar o que historicamente se construiu como modus operandi das experiências sociais femininas, como coloca a pedagogia feminista: não separar sujeito e objeto, razão e afeto; não 
negar as ligações pessoais de estímulo ao conhecimento e a intuição; mergulhar no pensamento divergente, arte e na estética; trabalhar orientado pelo comunitarismo e pela cooperação. Estabelecer uma lógica de produção de conhecimento e de trabalho que não esteja pautada em emular as características masculinizantes do campo científico, como competição e hostilidade, recriando sensibilidades no cotidiano escolar.

\section{Referências}

ARROYO, M. G. 2013. Currículo, território em disputa. Petrópolis, Vozes, 375 p.

BARCA, I.; MARTINS, E.; SCHMIDT, M. A. 2011. Jörn Rüsen e o ensino de História. Curitiba, UFPR, $168 \mathrm{p}$.

BIESTA, Gert. (2012). Boa educação na era da mensuração. Cadernos de Pesquisa, vol.42 (n.147): 808-825. Disponível em https://dx.doi.org/10.1590/s010015742012000300009

CANDAU, V.; MOREIRA, A. F. 2013. Multiculturalismo: diferenças culturais e práticas pedagógicas. Petrópolis Vozes, 245 p.

CASTRO-GÓMEZ, S.; GROSFOGUEL, R. 2007. El giro decolonial: reflexiones para una diversidad epistémica más allá del capitalismo global. Bogotá, Siglo del Hombre Editores; Universidad Central, Instituto de Estudios Sociales Contemporáneos y Pontificia Universidad Javeriana, Instituto Pensar, 308 p.

CERRI, L. F. 2011. Ensino de História e consciência histórica. Rio de Janeiro, Editora FGV, 136 p.

FONSECA, S. G. Ser Professor no Brasil. História oral de vida. Campinas, Papirus, 230 p. KELLNER, D. A cultura da mídia. Estudos culturais: identidade e política entre o moderno e o pós-moderno. Bauru, EDUSC, 2001, 454 p.

LEGOFF, J. 1990. História e memória. Campinas, Editora da UNICAMP, 476 p.

LOPES, A.C., MACEDO, E. 2011. Teorias do Currículo. São Paulo, Cortez, 279 p.

LOPES, A. C. 1997. Conhecimento Escola em Química. Processo de mediação didática da ciência. Química Nova, vol. 20 (n.5): 563-568.

LUGONES, María. 2008. Colonialidad y Género. Tábula Rasa, (n.9): 73-101.

LUGONES, María. 2014. Rumo a um feminismo descolonial. Estudos Feministas, vol.22 (n.3): 935-952. 
MATTOS, I. R. 2006. "Mas não somente assim!" Leitores, autores, aulas como texto e o ensino-aprendizagem de História. Tempo [online], vol.11 (n.21): 5-16.

MONTEIRO, A. M. F. C. 2007. Professores de História: entre saberes e práticas. Rio de Janeiro, Mauad X, 262 p.

QUIJANO, A. 2005. Colonialidade do poder, Eurocentrismo e América Latina. In: E. LANDER. A colonialidade do saber: eurocentrismo e ciências sociais. Perspectivas latino-americanas. Buenos Aires, CLACSO, Consejo Latinoamericano de Ciencias Sociales, 246 p. Disponível em: http://biblioteca.clacso.edu.ar/clacso/sur-sur/20100624103322/ 12_Quijano.pdf. Acesso em: 10/08/2017.

ROCHA, H. 2014. A presença do passado na aula de História. In: M. MAGALHÃES [et.al.]. Ensino de História: usos do passado, memória e mídia. Rio de Janeiro: FGV, 472 p.

SILVA, T. T. 2016. Documentos de Identidade. Uma introdução às teorias do currículo. Belo Horizonte, Autêntica, 156 p.

WALSH, C. 2008. Interculturalidad crítica y pedagogía de-colonial: apuestas (des)de el insurgir, re-existir y re-vivir. Quito, Universidad Andina Simón Bolívar sede Ecuador.

Artigo recebido em 25 de outubro de 2017 e aprovado em 10 de janeiro de 2018. 